\title{
RESEARCH WORKS ON TREATMENT OF ASH GENERATED BY INCINERATORS IN ORDER TO DIMINISH THEIR POLLUTION POTENTIAL
}

 \\ 1 National Research and Development Institute for Industrial Ecology ECOIND, 71-73. Drumul \\ Podu Dambovitei, 060652, Bucharest, Romania, tehnologi@incdecoind.ro
}

\begin{abstract}
Waste represents one of the most important topics in the field of environmental protection due to induced pollution on all environmental media (water, air and soil). From the three known categories of waste (inert, non-hazardous, and hazardous), the last one rises serious issues from the point of view of technical and financial management. A special category of hazardous waste according to national regulations is represented by medical waste that cannot be disposed without adequate treatment. Experimental results obtained on treatment of bottom and filter ashes resulted from incineration of medical waste are presented. Chemical analysis of waste samples and corresponding leachates has revealed that values of many indicators exceed maximum admissible values for storage on hazardous waste deposits. Two variants of technological flows were developed for treatment of bottom and filter ash waste: washing under mixing with acid solution followed by filtration of obtained mixtures and incorporation of waste in "concrete" type matrices through mixing with sand and cement. These two technological flows variants had as final result waste types for which leaching indicators values were situated below the legal norms for storage on nonhazardous waste deposits.
\end{abstract}

Keywords: Bottom ash, Filter ash, Medical waste, Waste treatment

\section{Introduction}

Wastes are representing one of the most important issues in environmental protection due to pollution upon environmental media (water, air, soil). Management of hazardous waste is causing serious problems both in terms of technical and financial issues.

A special category of hazardous waste is represented by medical waste that in accordance with national legislation can not be disposed without proper treatment. Medical wastes are generated within the diagnosys activities, post surgery recovery, surveillance and prevention of various diseases and during medical research activities. Medical wastes generated within medical units are classified in two distinct groups [1]:

- Non-hazardous medical waste: municipal waste generated by technical-medical, administrative and medical accommodation activities;

- Hazardous medica waste: anatomico-pathologic, liquid or solid infected, sharp or cutting, chemical and pharmaceutical waste.

In accordance with national legislation [2-5] medical waste can not be disposed without treatment. There are three known methods for medical waste treatment: chemical disinfection, thermal sterilisation and incineration. The most important factors based on which optimum treatment method is selected are: the ration between initial and final waste mass; quantity of waste; available treatment technologies and equipments; location of treatment installation; initial investment and operating costs; legislation. Incineration represents the most used method for medical waste treatment [6] but its appliance is causing pollution on all environmental media. 
When was first applied (1970) it seems to be a benefic approach due to the fact that significant energy quantities were obtained [7]. In Romania, application of incineration of waste is in the incipient phase [7], co-incineration process being more developed. In the last years due to national legislation, harmonised with the EU one, the medical waste incineration started to be applied on large scale representing until now the only viable solution for medical waste disposal.

But, beside air pollution with dioxins, PCBs and heavy metals, soil pollution with heavy metals, chlorides and sulphates occurs also. Medical waste incineration technique is applied on large scale both in US and Europe being considered the safest method beside its environmental drawbacks [8-9]. Research studies [10-11] showed that the same problems related with high concentrations of heavy metals and other compounds appears for the ash generated during medical waste incineration.

For example the bottom ash analyses showed zinc, cadmium, lead and nickel concentrations between $0.5-25071 \mathrm{mg} / \mathrm{kg}$ [10]. The compounds which contains those heavy metals are hard to be slightly soluble, concentrations of maximum $2.85 \mathrm{mg} / \mathrm{kg}$ being found in leachate.

Due to pollution issues that occur during disposal of ashes generated by incineration process, the literature in the field is focussing on various methods for ash stabilisation prior to landfilling [12]. These methods for bottom and filter ash treatment are representing the theme of this paper.

\section{Materials and methods}

Five bottom ash and five filter ash samples were used during the experiments. These were sampled in five consecutive days from a medical waste incineration facility. Bottom ash samples were codified with odd numbers (P1; P3; P5; P7; P9) and their corresponding filter ash samples were codified with even numbers (P2; P4; P6; P8; P10). All samples were sieved at $0.2 \mathrm{~mm}$ and then homogenised and analysed from the chemical point of view. In the same time the leachates corresponding to ash samples were also analysed (leachates samples were codified LPi, $\mathrm{i}=1-10$ ) in accordance with the Order of Ministry of Environment and Water Administration no. 95/2005. All analyses were performed using standardised methods.

\section{Results and discussion}

The results obtained at chemical characterisation of ash samples and their corresponding leachates are presented in Table 1 for bottom ash samples and Table 2 for filter ash samples.

The results presented as "<" means that indicators value was below the method detection limit. Values marked with blue are exceeding the normed values for waste disposal to non-hazardous deposits, and those marked with red are exceeding the normed values for waste disposal on hazardous waste (in accordance with Order 95/2005). 
Tab. 1 Chemical characterisation of bottom ash samples and their leachates

\begin{tabular}{|c|c|c|c|c|c|c|c|c|c|c|}
\hline \multirow[t]{2}{*}{ Indicator } & \multicolumn{10}{|c|}{ Sample type and values expressed in $\mathrm{mg} / \mathrm{kg} \mathrm{d.m}$. } \\
\hline & P1 & LP1 & P3 & LP3 & P5 & LP5 & P7 & LP7 & P9 & LP9 \\
\hline $\mathrm{pH}$ & - & 9,67 & - & 9,23 & - & 9,42 & - & 9,69 & - & 9,7 \\
\hline As & 20,18 & 0,01 & 47,89 & 0,21 & 35,7 & 0,34 & 37,63 & 0,38 & 26,11 & 0,17 \\
\hline $\mathrm{Ba}$ & 4510 & 2,59 & 4464 & 2,56 & 5373 & 3,36 & 2830 & 3,65 & 2431 & 3,61 \\
\hline $\mathrm{Cd}$ & $<5$ & 0,01 & $<5$ & 0,85 & $<5$ & 1,39 & $<5$ & 1,66 & $<5$ & 0,17 \\
\hline $\mathrm{Cr}$ & 1720 & 0,41 & 2303 & 2,39 & 1341 & 0,83 & 1733 & 0,88 & 2131 & 0,49 \\
\hline $\mathrm{Cu}$ & 1795 & 0,16 & 2963 & 0,95 & 2682 & 1,13 & 2622 & 1,06 & 2191 & 0,63 \\
\hline $\mathrm{Hg}$ & 27,62 & 0,76 & 36,71 & 0,77 & 25,22 & 0,63 & 19,6 & 0,38 & 25,25 & 0,38 \\
\hline Mo & $<10$ & 0,57 & $<10$ & 0,89 & $<10$ & 0,16 & $<10$ & 0,12 & $<10$ & 0,14 \\
\hline $\mathrm{Ni}$ & 1953 & 2,32 & 2218 & 2,65 & 1350 & 3,87 & 1742 & 5,13 & 1891 & 6,21 \\
\hline $\mathrm{Pb}$ & 144,1 & 5,82 & 124,3 & 48,96 & 145,4 & 10,15 & 176,8 & 11,49 & 118,1 & 5,67 \\
\hline $\mathrm{Sb}$ & 95,78 & 0,21 & 77,52 & 0,19 & 78,67 & 0,17 & 103,7 & 0,36 & 59,58 & 0,24 \\
\hline Se & 9,95 & $<7 \times 10^{-5}$ & 11,38 & $<7 \times 10^{-5}$ & 11,24 & $<7 \times 10^{-5}$ & 5,11 & $<7 \times 10^{-5}$ & 11,21 & 0,01 \\
\hline $\mathrm{Zn}$ & 4278 & 226,9 & 4063 & 453,4 & 3910 & 544,7 & 4416 & 619,2 & 3938 & 170,6 \\
\hline Chlorides & 50122 & 28400 & 45501 & 28400 & 51848 & 39050 & 52347 & 31950 & 53500 & 42600 \\
\hline Sulphates & 33104 & 2386 & 30302 & 4732 & 29276 & 6172 & 32401 & 2633 & 31929 & 3250 \\
\hline DOC & - & 336 & - & 164 & - & 143 & - & 365 & - & 399 \\
\hline TDS & - & 31200 & - & 23200 & - & 31100 & - & 36600 & - & 44300 \\
\hline
\end{tabular}

Tab. 2 Chemical characterisation of filter ash samples and their leachates

\begin{tabular}{|c|c|c|c|c|c|c|c|c|c|c|}
\hline \multirow[t]{2}{*}{ Indicator } & \multicolumn{10}{|c|}{ Sample type and values expressed in $\mathrm{mg} / \mathrm{kg}$ d.m. } \\
\hline & P2 & LP2 & P4 & LP4 & P6 & LP6 & P8 & LP8 & P10 & LP10 \\
\hline $\mathrm{pH}$ & - & 6,31 & - & 6,26 & - & 6,3 & - & 6,27 & - & 6,51 \\
\hline As & 78,22 & 2,2 & 56,31 & 0,66 & 67,28 & 0,47 & 68,45 & 0,41 & 44,79 & $<5$ \\
\hline $\mathrm{Ba}$ & 897,4 & 3,71 & 763,8 & 2,28 & 930,4 & 2,53 & 765,1 & 2,01 & 823,3 & 2,75 \\
\hline $\mathrm{Cd}$ & $<5$ & 16,48 & $<5$ & 13,06 & $<5$ & 10,65 & $<5$ & 11,5 & $<5$ & 7,14 \\
\hline $\mathrm{Cr}$ & 925,3 & 0,14 & 850,5 & 0,34 & 942,1 & 0,13 & 851,3 & 0,11 & 928,7 & 0,27 \\
\hline $\mathrm{Cu}$ & 3263 & 9,33 & 3955 & 8,02 & 4219 & 4,42 & 5436 & 4,28 & 4130 & 1,37 \\
\hline $\mathrm{Hg}$ & $<5$ & 0,31 & $<5$ & 0,29 & $<5$ & 0,28 & $<5$ & 0,27 & $<5$ & 0,26 \\
\hline Mo & $<10$ & 0,13 & $<10$ & 0,16 & $<10$ & 0,12 & $<10$ & 0,14 & $<10$ & 0,31 \\
\hline $\mathrm{Ni}$ & 969,4 & 13,45 & 779,4 & 10,47 & 858,5 & 8,65 & 937,6 & 8,79 & 922,9 & 6,43 \\
\hline $\mathrm{Pb}$ & 6210 & 69,95 & 7297 & 66,91 & 7729 & 97,51 & 8916 & 110,8 & 7236 & 70,2 \\
\hline $\mathrm{Sb}$ & 929,1 & 0,29 & 761,8 & 0,18 & 904,1 & 0,26 & 798,6 & 0,33 & 685,9 & 0,14 \\
\hline $\mathrm{Se}$ & 29,37 & 0,92 & 29,23 & 0,77 & 28,87 & 0,76 & 38,64 & 0,07 & 33,18 & 0,66 \\
\hline $\mathrm{Zn}$ & 30330 & 6303 & 33805 & 3746 & 36360 & 6528 & 43429 & 8171 & 35987 & 4981 \\
\hline
\end{tabular}


INCD ECOIND - INTERNATIONAL SYMPOSIUM - SIMI 2016 "THE ENVIRONMENT AND THE INDUSTRY", PROCEEDINGS BOOK

\begin{tabular}{|c|l|l|l|l|l|l|l|l|l|l|}
\hline Chlorides & 198679 & 150875 & 276673 & 187182 & 267355 & 205900 & 254056 & 230750 & 236046 & 204125 \\
\hline Sulphates & 238990 & 67970 & 180227 & 70531 & 174996 & 82135 & 172566 & 70695 & 148980 & 68140 \\
\hline DOC & - & 116,9 & - & 408 & - & 471 & - & 542 & - & 285 \\
\hline TDS & - & 337600 & - & 389800 & - & 409200 & - & 432000 & - & 420000 \\
\hline
\end{tabular}

Analyse of data presented in Table 1, shows that there is a high variability for $\mathrm{As}, \mathrm{Ba}, \mathrm{Cu}$ both for initial waste samples and their leachates. For all samples $\mathrm{Hg}$ is exceeding the imposed value for disposal in non-hazardous deposits but is lower than imposed value for disposal in hazardous waste deposits. In 3 of 5 cases same conclusion is valid for $\mathrm{Pb}$ and in 2 of 5 cases for $\mathrm{Cd}$. The indicators that are raising serious issues are $\mathrm{Zn}$ and chlorides for which obtained values (with the exception of LP9) are exceeding the imposed limits for disposal in hazardous waste deposits.

Data from Table 2 are showing that filter ash samples has an more uniform composition compared with bottom ash samples. For all analysed samples $\mathrm{Hg}$ is exceeding the limit for disposal on nonhazardous deposits but is below limit for disposal on hazardous waste deposits. Same situation was found in 4 of 5 cases for Se, 2 of 5 cases for Ni and 1 of 5 cases for As. But in comparison with bottom ash, for filter ash exceedings of admissible values for disposal on hazardous waste deposits were recorded for $\mathrm{Cd}, \mathrm{Pb}, \mathrm{Zn}$, chlorides, sulphates and TDS. Aside of above mentioned analyses, the carbonates content was determined. The values for this indicator were situated between $5.53 \%(\mathrm{P} 1)$ and $10.45 \%$ (P9) for bottom ash samples and between $0.79 \%(\mathrm{P} 4)$ and $3.21 \%$ (P6) for filter ash samples. High content of carbonates bottom ashes is confirmed also by $\mathrm{pH}$ values of their leachates which were situated in alkaline domain (more than $9 \mathrm{pH}$ units). For filter ash samples $\mathrm{pH}$ values were situated in neutral domain confirming low carbonate content.

Starting from these data two treatment technologies were developed:

V1 - washing under mixing with acid solution $\left(\mathrm{H}_{2} \mathrm{SO}_{4}\right)$ followed by filtration of obtained mixtures; V2 - incorporation of waste in "concrete" type matrices through mixing with sand and cement.

Working parameters for the first technological variant were: weigh ration ash/acid solution of 1/5; temperature of $25 \mathrm{C}$; mixing at $400 \mathrm{rpm}$; washing time $1 \mathrm{~h}$; filtering on filter paper for $1 \mathrm{~h}$; drying at room temperature. Used samples were P9 (bottom ash with highest chlorides content in its leachate) for which a acid solution with weight concentration of $3.4 \%$ and P2 (filter ash with the most indicators exceeding normed values) for which a acid solution with weight concentration of $0.5 \%$ was used. Concetrations of acid solutions were determined by stoechimetry based on carbonate content of those two ash samples. Liquid samples obtained after washing codified P2A and P9A and their corresponding leachates codified LP2A and LP9A were characterised from chemical point of view and the results are presented in Table 3.

Tab. 3 Chemical characterisation of washed ash samples and their leachates

\begin{tabular}{|c|c|c|c|c|}
\hline \multirow{2}{*}{ Indicator } & \multicolumn{4}{|c|}{ Sample type and values expressed in mg/kg d.m. } \\
\cline { 2 - 5 } & P2A & P9A & LP2A & LP9A \\
\hline pH & 6,0 & 4,45 & 8,7 & $<, 95$ \\
\hline As & 0,16 & $<0,07$ & $<0,07$ & 1,34 \\
\hline Ba & 4,92 & 3,57 & 4,29 & $<0,01$ \\
\hline Cd & 40,5 & $<0,01$ & $<0,01$ & 0,25 \\
\hline Cr & $<0,01$ & $<0,01$ & 9,96 & 0,03 \\
\hline Hg & 74,5 & 5,49 & 0,01 & $<0,005$ \\
\hline Mo & 0,008 & 0,006 & 0,005 & 0,48 \\
\hline
\end{tabular}




\begin{tabular}{|c|c|c|c|c|}
\hline $\mathbf{N i}$ & 63,3 & 88,0 & $<0,03$ & 1,37 \\
\hline Pb & 127 & 0,58 & $<0,07$ & $<0,07$ \\
\hline Sb & 2,62 & $<0,06$ & 0,75 & 0,37 \\
\hline Se & $<0,04$ & $<0,04$ & 0,26 & $<0,04$ \\
\hline Zn & 16275 & 482 & 0,13 & 0,41 \\
\hline Chlorides & 120700 & 35500 & 5500 & 3250 \\
\hline Sulphates & 64800 & 9280 & 16830 & 1650 \\
\hline DOC & 50,2 & 112 & 20,6 & 120 \\
\hline TDS & 311900 & 73250 & 43200 & 22300 \\
\hline
\end{tabular}

All leachates' indicators were situated below imposed values for disposal on non-hazardous waste deposits. For this technologica variant, washed ashes were analysed via $X$ ray fluorescence and significant modifications on their composition was observed due to the carbonates elimination. Variation of the significant metals concentrations in washed sample vs. initial sample is presented as percentage in Figure 1.

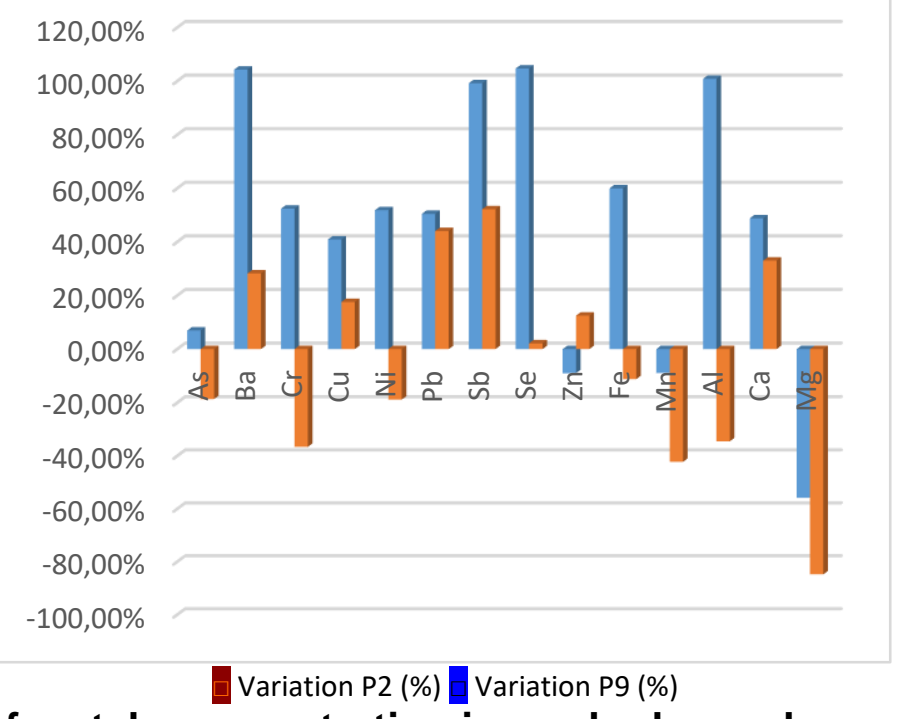

Fig.1 Variation of metals concentration in washed samples vs. initial samples

For the second technological variant usual building materials were used (sand with granulation of $1 \mathrm{~mm}$ and cememnt) that were mixed with ash samples in proportions similar with those of B200 concrete type. Same waste samples (P9 and P2) were used. Six "concrete" type matrices were realised and were codified as B1-B6 (see Figure 2):

B1: bottom ash P9 - 1 part; sand -9 parts; cement -2 parts

B2: bottom ash P9 - 1 part; sand - 4 parts; cement -1 part

B3: filter ash P2 - 1 part; sand -9 parts; cement -2 parts

B4: filter ash P2 - 1 part; sand -4 parts; cement -1 part

B5: bottom ash washed with acid solution- 1 part; sand - 4 parts; cement -1 part

B6: filter ash washed with acid solution - 1 part; sand - 4 parts; cement -1 part 


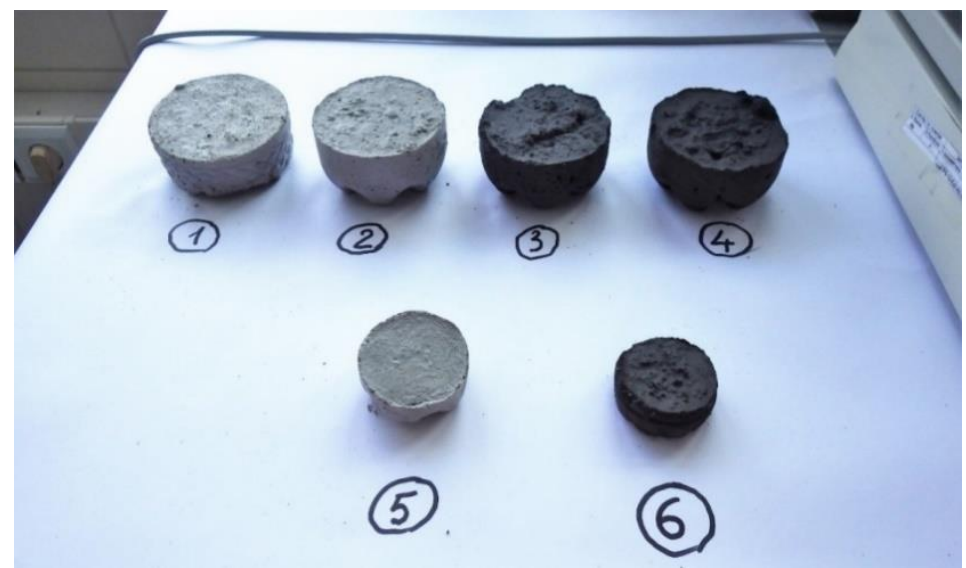

Fig.2 - Concrete samples B1-B6

Obtained products (concrete samples) were subject to leaching in a 1/10 ratio in accordance with the procedure established by Order 95/2005 and the obtained results are presented in Figure 3.

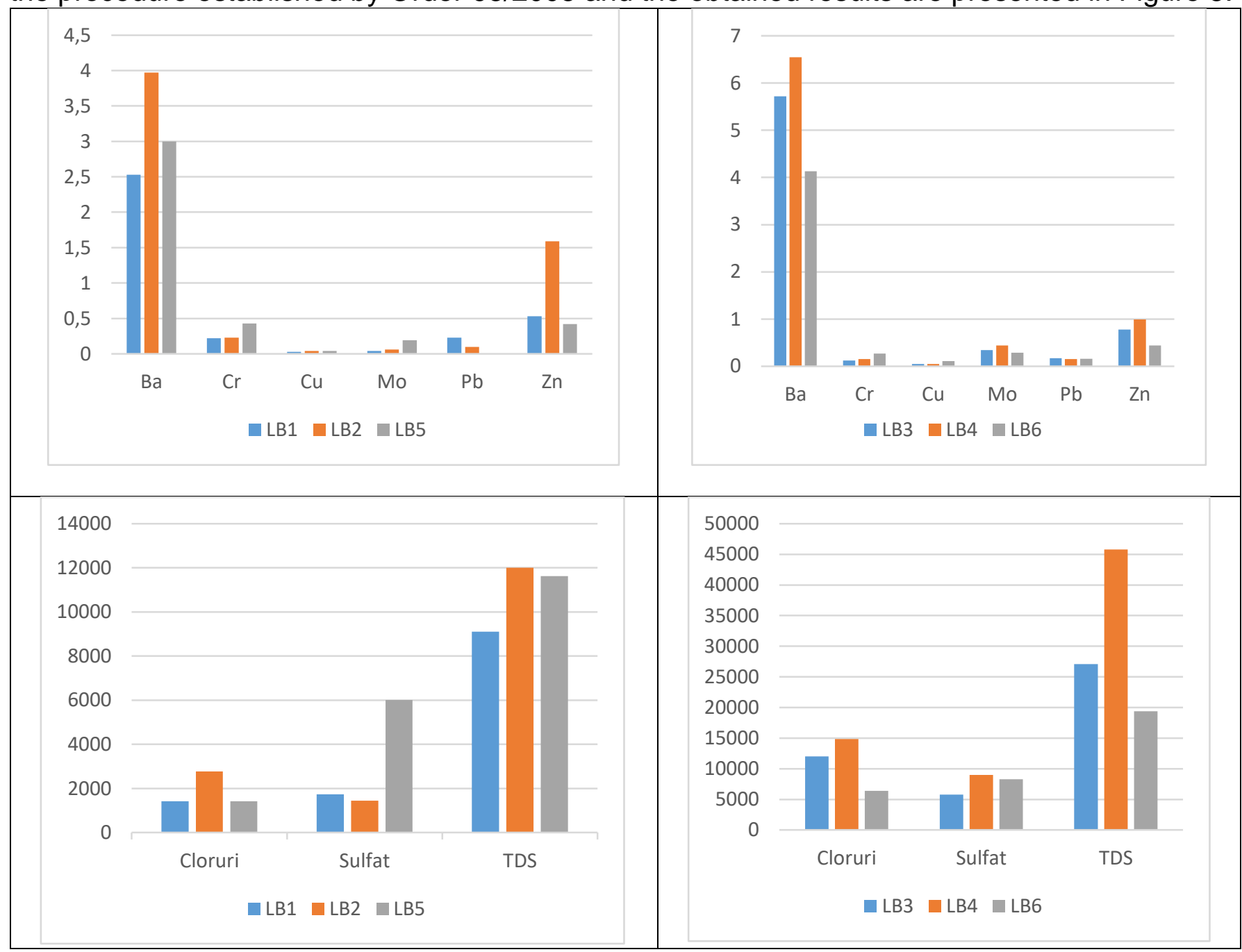

Fig.3 Values of significant indicators from concrete samples leachates

Incorporation of bottom and filter ashes within concrete type matrices has as effect drastic reduction of analysed indicators within their leachates compared with initial ashes samples. All 
inicators values for all six types of matrices are situated below normed values imposed for their disposal to non-hazardous waste deposits.

\section{Conclusions}

Analysis on chemical composition of bottom and filter ashes sampled for 5 consecutive days, showed a non-uniformity due to the daily modifications of medical waste types subject to incineration.

The two proposed technological variants for treatment of bottom and filter ashes resulted in obtainance of bew wastes for which leaching indicators present values that are complying with legal norms for disposal on nob-hazardous waste deposits.

\section{Acknowledgements}

The research works presented in this paper were obtained within the Nucleu project PN 1625.03.01 financed by National Authority for Scientific Research and Innovation.

\section{References}

1. Gnandt F, Vasiu R, Lungu D. (2011) - Tratarea deseurilor periculoase din activitati medicale, A XI-a Conferinta Nationala cu participare internationala, „Profesorul Dorin Pavel-fondatorul hidroenergeticii romanesti", Sebes, (in Romanian) p. 531-538;

2. Order of Health Ministry no. 1226/2012 for approval of Technical norms for management of waste generated by medical activities and the Methodology for collection of data for national database on wastes resulted from medical activities;

3. Law $211 / 2011$ on waste regime;

4. GD 856/2002 regarding waste management records and for approval of list of wastes, including hazardous waste;

5. Order of Ministry of Environment and Water Administration no. 95/2005 on acceptance criteria and preliminary acceptance procedures for wastes at disposal and national list of accepted wastes on each waste deposit class;

6. www.agir.ro/buletine/833.pdf, Popescu A., Tratarea prin metode alternative a deseurilor periculoase provenite din unitatile sanitare, (In Romanian);

7. www.green-report.ro/, Green Report, Incinerarea deseurilor, solutie sau pericol pentru mediu?, p.1-7; (In Romanian)

8. www.3.epa.gov/epawaste/nonhaz/industrial/medical/mwpdfs/modguidl/4.pdf, The Council of State Governments, Treatment, Destruction \& Disposal, p.21-30;

9. www.who.int/water_sanitation_health/medicalwaste/077to112pdf, Treatment and disposal technologies for health-care waste, p.77-112;

10. Meriem EL Bakkali, Meriem Bahri, Said Gmouh, Hassan Jaddi, Mohammed Bakkali, Amin Laglaoui, Mohammed EL Mzibri (2013), Characterization of bottom ash from two hospital waste incinerators in Rabat, Morocco, Waste Management \& Research, vol.3, no. 12, 1228-1236;

11. Wielgosinski G., Wasiak D., Zawadzka A. (2014), The use of sequential extraction for assessing environmental risks of waste incineration bottom ash, Ecol. Chem. Eng. S. vol 21 (3), p. 413-423;

12. www.iswa.org/uploads/tx iswaknowledgebase/kalogirou.pdf, Kalogirou E., Themelis N., Samaras P., Karagiannidis A., Fly Ash Characteristics From Waste to Energy Facilities and Processes For Ash Stabilization. 